\title{
Hemodilution during cardiopulmonary bypass is an independent risk factor for acute renal failure in adult cardiac surgery
}

\author{
K. Karkouti, MD, MSc ${ }^{a, b}$ \\ W. S. Beattie, MD, PhD ${ }^{a}$ \\ D. N. Wijeysundera, MD ${ }^{a, b}$ \\ V. Rao, MD, PhD' \\ C. Chan, MD ${ }^{\mathrm{d}}$ \\ K. M. Dattilo, $M D^{\mathrm{a}}$ \\ G. Djaiani, $M^{\mathrm{a}}$ \\ J. Ivanov, $\mathrm{PhD}^{\mathrm{C}}$ \\ J. Karski ${ }^{\mathrm{a}}$ \\ T. E. David, MDc
}

Background: This observational study sought to determine whether the degree of hemodilution during cardiopulmonary bypass is independently related to perioperative acute renal failure necessitating dialysis support.

Methods: Data were prospectively collected on consecutive patients undergoing cardiac operations with cardiopulmonary bypass from 1999 to 2003 at a tertiary care hospital. The independent relationship was assessed between the degree of hemodilution during cardiopulmonary bypass, as measured by nadir hematocrit concentration, and acute renal failure necessitating dialysis support. Multivariate logistic regression was used to control for variables known to be associated with perioperative renal failure and anemia.

Results: Of the 9080 patients included in the analysis, $1.5 \%(\mathrm{n}=134)$ had acute renal failure necessitating dialysis support. There was an independent, nonlinear relationship between nadir hematocrit concentration during cardiopulmonary bypass and acute renal failure necessitating dialysis support. Moderate hemodilution (nadir hematocrit concentration, 21\%-25\%) was associated with the lowest risk of acute renal failure necessitating dialysis support; the risk increased as nadir hematocrit concentration deviated from this range in either direction $(P=.005)$. Compared with moderate hemodilution, the adjusted odds ratio for acute renal failure necessitating dialysis support with severe hemodilution (nadir hematocrit concentration $<21 \%$ ) was 2.34 (95\% confidence interval, 1.47-3.71), and for mild hemodilution (nadir hematocrit concentration $>25 \%$ ) it was 1.88 (95\% confidence interval, 1.02-3.46).

Conclusions: Given that there is an independent association between the degree of hemodilution during cardiopulmonary bypass and perioperative acute renal failure necessitating dialysis support, patient outcomes may be improved if the nadir hematocrit concentration during cardiopulmonary bypass is kept within the identified optimal range. Randomized clinical trials, however, are needed to determine whether this is a cause-effect relationship or simply an association. 


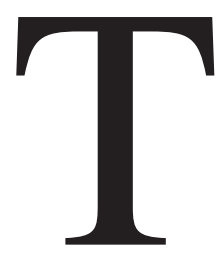

his study examined the relationship between the degree of hemodilution during cardiopulmonary bypass (CPB) in cardiac operations and postoperative acute renal failure (ARF) necessitating dialysis support (ARFD). Renal failure necessitating dialysis support is a devastating complication of cardiac surgery: it occurs in $1 \%$ to $5 \%$ of patients and is strongly associated with serious adverse events, including death. ${ }^{1-3}$

The current practice of $\mathrm{CPB}$, which entails the addition of 1.5 to $2 \mathrm{~L}$ or more of nonhematic fluids (crystalloid and colloid fluids used to prime the CPB circuit) to the patient's blood volume, frequently results in marked hemodilution, often to hematocrit concentrations less than $20 \%$. This practice, which is in contrast to the early days of cardiac surgery, when allogeneic blood was used as a prime to avoid hemodilution, was adapted primarily to reduce the use of blood products. ${ }^{4}$ Although this practice has now been accepted for more than 4 decades, there is a renewed debate about the optimal degree of hemodilution during CPB., ${ }^{5,6}$ Recent studies have found a direct association between the severity of hemodilution during CPB and perioperative morbidity and mortality. ${ }^{6-9}$ More specifically, there is a growing body of evidence linking low hematocrit concentrations during $\mathrm{CPB}$ with an increased risk of renal dysfunction. ${ }^{6,10,11}$ Earlier evidence, however, suggested that hemodilution confers protection against renal injury. ${ }^{12,13}$

Although seemingly contradictory, these findings may be congruent if the relationship between the degree of hemodilution during $\mathrm{CPB}$ and post-cardiac operation ARF is more U-shaped than linear. Hematocrit concentrations at the trough of the curve would confer the lowest risk of renal dysfunction, with the risk increasing as the hematocrit deviates from this optimal concentration in either direction. The objective of this study was to determine whether such an optimal hematocrit concentration exists by assessing the relationship between nadir hematocrit concentration (nHct) during CPB and postoperative ARF-D while controlling for multiple perioperative variables known to be related to perioperative renal dysfunction and anemia. Such a finding would be important for it would suggest a means of protecting the kidneys against injury during cardiac operations.

\section{Methods}

After institutional ethics approval, data on consecutive adult ( $\geq 18$ years) patients undergoing cardiac operation with $\mathrm{CPB}$ at the Toronto General Hospital from June 1999 to June 2003 were identified from a prospectively collected database, the details of which have been previously described. ${ }^{14,15} \mathrm{~A}$ full-time research nurse, who was blinded to the details of this study and to the intraoperative hematocrit data, adjudicated all outcomes from patients' medical records. Attending anesthesiologists, surgeons, and perfusionists collected all preoperative and intraoperative data, with the exception of blood-product transfusion data. A research assistant obtained the transfusion data from the transfusion laboratory's database (Hemocare, Mediware Information Systems, Melville, NY).

\section{Study Setting and Clinical Practice}

The Toronto General Hospital is a tertiary care teaching hospital affiliated with the University of Toronto. A full range of adult cardiac surgery procedures, including such complex procedures as congenital heart disease repair and heart transplantation, is performed at this hospital.

During the study period, patients were managed according to standardized clinical protocols as described below.

Anesthetic management. Fast-track anesthesia with fentanyl $(10-20 \mu \mathrm{g} / \mathrm{kg})$, midazolam $(0.1 \mathrm{mg} / \mathrm{kg})$, pancuronium $(0.15-0.20$ $\mathrm{mg} / \mathrm{kg})$, isoflurane $(0.5 \%-1.5 \%)$, and propofol $\left(0.5-4 \mathrm{mg} \cdot \mathrm{kg}^{-1}\right.$. $\mathrm{h}^{-1}$ ) was used. Patients were routinely monitored with pulmonary artery catheters. Transesophageal echocardiography was routinely used except for patients undergoing isolated aortocoronary bypass. Epiaortic scanning was not routinely used. Antifibrinolytic drugs - tranexamic acid $(50-100 \mathrm{mg} / \mathrm{kg})$ or aprotinin $\left(6 \times 10^{6} \mathrm{U}\right)$, depending on bleeding risk-were used prophylactically in every patient undergoing $\mathrm{CPB}$.

CPB management. Anticoagulation was achieved with heparin to maintain an activated clotting time more than 480 seconds. The CPB circuit was primed with $1.8 \mathrm{~L}$ of lactated Ringer's solution and $50 \mathrm{~mL}$ of $20 \%$ mannitol. Albumin (25\%) and synthetic colloids (Pentaspan; Bristol-Myers Squibb Canada Inc, Montreal, Quebec, Canada) were added to the circuit as needed. Management of CPB included systemic temperature drift to $34^{\circ} \mathrm{C}$, alpha-stat $\mathrm{pH}$ management, targeted mean perfusion pressure between 50 and $70 \mathrm{~mm} \mathrm{Hg}$, and pump flow rates of 2.0 to $2.4 \mathrm{~L}$. $\min ^{-1} \cdot \mathrm{m}^{-2}$. Myocardial protection was achieved with intermittent antegrade and, occasionally, retrograde blood cardioplegia. When necessary, deep hypothermic circulatory arrest (DHCA) was achieved by cooling to $20^{\circ} \mathrm{C}$ with or without retrograde cerebral perfusion. Furosemide was administered in response to persistent oliguria or hyperkalemia.

During CPB, red blood cell concentrate (leukoreduced allogeneic or autologous) was transfused to maintain the hematocrit concentration more than $17 \%$. Pericardial blood was salvaged into the cardiotomy suction reservoir and was reinfused via the CPB circuit as long as patients were anticoagulated. After separation from CPB, heparin was neutralized with protamine sulphate, $1 \mathrm{mg}$ per $100 \mathrm{U}$ of heparin, to achieve an activated clotting time within $10 \%$ of baseline. After CPB, red blood cell concentrate was transfused to maintain the hematocrit more than $21 \%$ to $24 \%$ in stable patients and more than $27 \%$ in bleeding or unstable patients.

\section{Dependent Variable}

ARF was defined as a new requirement for postoperative dialysis.

\section{Independent Variables}

The primary variable of interest was nHct during CPB. Variables that may be related to perioperative renal dysfunction ${ }^{1-3,16}$ or anemia $^{15,17,18}$ were considered for inclusion in the multivariate analysis as confounding variables (Table 1). 
TABLE 1. Bivariate relationship of independent variables with ARF-D

\begin{tabular}{|c|c|c|c|}
\hline & ARF-D & No ARF-D & $P$ Value \\
\hline \multicolumn{4}{|l|}{ Preoperative patient variables } \\
\hline Age, y (mean $\pm S D)$ & $64 \pm 14$ & $62 \pm 12$ & .2 \\
\hline \multicolumn{4}{|l|}{ Sex } \\
\hline Male & $90(1.3 \%)$ & 6708 & \multirow[t]{2}{*}{.04} \\
\hline Female & $44(1.9 \%)$ & 2238 & \\
\hline Height, $\mathrm{cm}($ mean $\pm \mathrm{SD})$ & $167 \pm 11$ & $169 \pm 11$ & .07 \\
\hline Weight, $\mathrm{kg}$ (mean $\pm \mathrm{SD})$ & $74 \pm 17$ & $79 \pm 16$ & $<.001$ \\
\hline \multicolumn{4}{|l|}{ Hypertension } \\
\hline No & $59(1.4 \%)$ & 4140 & \multirow[t]{2}{*}{.6} \\
\hline Yes & $75(1.5 \%)$ & 4806 & \\
\hline \multicolumn{4}{|l|}{ Diabetes mellitus } \\
\hline No & $81(1.2 \%)$ & 6693 & \multirow[t]{2}{*}{$<.001$} \\
\hline Yes & $53(2.3 \%)$ & 2253 & \\
\hline \multicolumn{4}{|c|}{$\begin{array}{l}\text { Peripheral vascular disease (history of aortoiliac, } \\
\text { femoropopliteal, or carotid disease or operation) }\end{array}$} \\
\hline No & $104(1.3 \%)$ & 7715 & \multirow[t]{2}{*}{.004} \\
\hline Yes & $30(2.4 \%)$ & 1231 & \\
\hline \multicolumn{4}{|c|}{$\begin{array}{l}\text { Cerebrovascular disease (history of stroke or transient } \\
\text { ischemic attacks) }\end{array}$} \\
\hline No & $116(1.4 \%)$ & 8134 & \multirow[t]{2}{*}{.07} \\
\hline Yes & $18(2.2 \%)$ & 812 & \\
\hline \multicolumn{4}{|c|}{ Hyperlipidemia (on treatment at time of operation) } \\
\hline No & $62(1.8 \%)$ & 3402 & \multirow[t]{2}{*}{.06} \\
\hline Yes & $72(1.3 \%)$ & 5544 & \\
\hline \multicolumn{4}{|l|}{ Smoker at time of operation } \\
\hline No & $60(1.9 \%)$ & 3145 & \multirow[t]{2}{*}{.02} \\
\hline Yes & $74(1.3 \%)$ & 5801 & \\
\hline \multicolumn{4}{|c|}{ Chronic obstructive pulmonary disease } \\
\hline No & $126(1.5 \%)$ & 8013 & \multirow[t]{2}{*}{.09} \\
\hline Yes & $8(0.8 \%)$ & 933 & \\
\hline \multicolumn{4}{|l|}{ Atrial fibrillation } \\
\hline No & $111(1.3 \%)$ & 8391 & \multirow[t]{2}{*}{$<.001$} \\
\hline Yes & $23(4.0 \%)$ & 555 & \\
\hline \multicolumn{4}{|c|}{ New York Heart Association class } \\
\hline | or || & $12(0.5 \%)$ & 2483 & \multirow[t]{2}{*}{$<.001$} \\
\hline III or IV & $122(1.8 \%)$ & 6463 & \\
\hline Left ventricular ejection $\mathrm{fr}$ & & & \\
\hline$\geq 40 \%$ & $84(1.2 \%)$ & 7149 & $<.001$ \\
\hline$<40 \%$ & $50(2.7 \%)$ & 1797 & \\
\hline Unstable angina (within 30 & & & \\
\hline No & $73(1.6 \%)$ & 5140 & .6 \\
\hline Yes & $61(1.4 \%)$ & 3806 & \\
\hline Recent myocardial infarcti & & & \\
\hline No & $109(1.4 \%)$ & 7519 & .4 \\
\hline Yes & $25(1.7 \%)$ & 1427 & \\
\hline Recent cardiac catheterize & & & \\
\hline No & $103(1.3 \%)$ & 8054 & $<.001$ \\
\hline Yes & $31(3.3 \%)$ & 892 & \\
\hline Congestive heart failure (a & & & \\
\hline No & $54(0.8 \%)$ & 7083 & $<.001$ \\
\hline Yes & $80(4.2 \%)$ & 1863 & \\
\hline Shock (at time of operatio & & & \\
\hline No & $119(1.3 \%)$ & 8831 & $<.001$ \\
\hline Yes & $15(11.4 \%)$ & 115 & \\
\hline
\end{tabular}


TABLE 1. Continued

\begin{tabular}{|c|c|c|c|}
\hline & ARF-D & No ARF-D & $P$ Value \\
\hline \multicolumn{4}{|l|}{ Endocarditis (at time of operation) } \\
\hline No & $132(1.5 \%)$ & 8877 & .4 \\
\hline Yes & $2(2.8 \%)$ & 69 & \\
\hline \multicolumn{4}{|l|}{ Intra-aortic balloon pump (inserted before operation) } \\
\hline No & $121(1.4 \%)$ & 8726 & $<.001$ \\
\hline Yes & $13(5.6 \%)$ & 220 & \\
\hline \multicolumn{4}{|l|}{$\begin{array}{l}\text { Renal function (creatinine; } \mu \mathrm{mol} / \mathrm{L} \text {; abnormal }>100 \text { in } \\
\quad \text { women; }>110 \text { in men) }\end{array}$} \\
\hline Normal & $54(0.7 \%)$ & 7270 & $<.001$ \\
\hline Abnormal & $80(4.6 \%)$ & 1676 & \\
\hline \multicolumn{4}{|l|}{$\begin{array}{l}\text { Severe renal dysfunction (creatinine; } \mu \mathrm{mol} / \mathrm{L} ;>200 \text { in } \\
\quad \text { women; }>220 \text { in men) }\end{array}$} \\
\hline No & $117(1.3 \%)$ & 8912 & $<.001$ \\
\hline Yes & $17(33.3 \%)$ & 34 & \\
\hline Hemoglobin concentration, g/dL (mean \pm SD) & $12 \pm 2$ & $13 \pm 1.5$ & $<.001$ \\
\hline \multicolumn{4}{|l|}{ Preoperative operative variables } \\
\hline \multicolumn{4}{|l|}{ Urgency } \\
\hline Elective & $88(1.1 \%)$ & 8252 & $<.001$ \\
\hline Urgent & $46(6.2 \%)$ & 694 & \\
\hline \multicolumn{4}{|l|}{ Repeat surgery } \\
\hline No & $110(1.3 \%)$ & 8236 & $<.001$ \\
\hline Yes & $24(3.3 \%)$ & 710 & \\
\hline \multicolumn{4}{|l|}{$\begin{array}{l}\text { Procedure (for multivariate analysis, } \mathrm{ACB} \text { and single valve } \\
\text { were combined) }\end{array}$} \\
\hline $\mathrm{ACB}$ & $52(0.9 \%)$ & 5835 & \\
\hline Single valve & $8(0.9 \%)$ & 895 & $<.001$ \\
\hline Other (complex) & $74(3.3 \%)$ & 2216 & \\
\hline \multicolumn{4}{|l|}{ Intraoperative variables } \\
\hline Lowest hematocrit during $\mathrm{CPB}, \%$ (mean $\pm \mathrm{SD}$ ) & $21 \pm 4$ & $23 \pm 4$ & $<.001$ \\
\hline Highest blood glucose during CPB, mmol/L (mean \pm SD) & $15.8 \pm 5.0$ & $14.2 \pm 3.9$ & $<.001$ \\
\hline $\begin{array}{l}\text { Lowest mean arterial pressure during } \mathrm{CPB}, \mathrm{mm} \mathrm{Hg} \text { (mean } \\
\quad \pm \mathrm{SD} \text { ) }\end{array}$ & $49 \pm 10$ & $48 \pm 10$ & .1 \\
\hline $\mathrm{CPB}$ duration, min (mean $\pm \mathrm{SD})$ & $143 \pm 72$ & $100 \pm 37$ & $<.001$ \\
\hline \multicolumn{4}{|l|}{ Deep hypothermic circulatory arrest } \\
\hline No & $124(1.4 \%)$ & 8653 & .01 \\
\hline Yes & $10(3.3 \%)$ & 293 & \\
\hline \multicolumn{4}{|l|}{ RBC transfusion on the day of operation } \\
\hline No & $26(0.5 \%)$ & 5056 & $<.001$ \\
\hline Yes & $108(2.7 \%)$ & 3890 & \\
\hline \multicolumn{4}{|l|}{$\begin{array}{l}\text { Excessive perioperative blood loss ( } \geq 5 \mathrm{U} \text { of } \mathrm{RBC} \\
\text { transfused on the day of operation) }\end{array}$} \\
\hline No & $78(0.9 \%)$ & 8213 & $<.001$ \\
\hline Yes & $56(7.1 \%)$ & 733 & \\
\hline \multicolumn{4}{|l|}{ Post-CPB variables } \\
\hline \multicolumn{4}{|l|}{$\begin{array}{l}\text { Difficult wean from CPB (requirement for inotropes or } \\
\text { intra-aortic balloon pump) }\end{array}$} \\
\hline No & $42(0.5 \%)$ & 7763 & $<.001$ \\
\hline Yes & $92(7.2 \%)$ & 1183 & \\
\hline \multicolumn{4}{|l|}{ Re-exploration } \\
\hline No & $90(1.1 \%)$ & 8434 & $<.001$ \\
\hline Yes & $44(7.9 \%)$ & 512 & \\
\hline
\end{tabular}




\begin{tabular}{lrr}
\hline & ARF-D & No ARF-D \\
\hline Low-output syndrome (use of inotropes or mechanical & \\
devices for $>30$ min to maintain blood pressure $>90$ & \\
mm Hg with a cardiac index $<2.2 \mathrm{~L} \cdot \mathrm{min}^{-1} \cdot \mathrm{m}^{-2}$ ) & & \\
No & $79(0.9 \%)$ & 8606 \\
Yes & $55(14.0 \%)$ & 340 \\
Adverse events (any of the following: arrhythmias requiring & \\
$\quad$ treatment, myocardial infarction, pulmonary & & 6021 \\
complications, stroke, sepsis) & $26(0.4 \%)$ & 2925 \\
No & $108(3.6 \%)$ & $<.001$ \\
Yes
\end{tabular}

$A R F-D$, Acute respiratory failure necessitating dialysis; $A C B$, aortocoronary bypass; $C P B$, cardiopulmonary bypass; $R B C$, red blood cell concentrate.

\section{Statistical Analysis}

SAS version 8.2 (SAS Institute Inc, Cary, NC) was used for statistical analyses. Database accuracy was measured by comparing all outlying values with patients' records and by reabstracting the medical records of 200 randomly selected patients. Whenever possible, missing values were completed from patients' records; otherwise, patients with missing categorical variable or nHct values were excluded. For continuous variables other than $\mathrm{nHct}$, missing values were imputed on the basis of the mean, according to postoperative renal status, for the entire sample. Patients requiring preoperative dialysis support were excluded from analysis.

The bivariate associations between the independent variables and ARF-D were assessed by using appropriate tests ( $t$ test, MannWhitney $U$ test, $\chi^{2}$ test, Fisher exact test, or Mantel-Haenszel test). The bivariate associations between $\mathrm{nHct}$ and other independent variables were assessed by the Pearson correlation test. Variables that were associated $(P \leq 0.1)$ with both ARF-D and nHct were included in the logistic regression analysis.

The mathematical relationships between the continuous independent variables and the probability of ARF-D (logit transformation) were assessed with restricted cubic spline functions. ${ }^{19-21}$ Variables that were not linearly related were either mathematically transformed or categorized for the logistic regression analysis. ${ }^{22} \mathrm{~A}$ Pearson correlation matrix was used to identify collinear independent variables. ${ }^{22}$

Two logistic regression models were constructed that controlled for all identified confounders (for correlated variables, only the most predictive was included in the multivariable analysis) with ARF-D as the dependent variable. In model 1, nHct was included in its quadratic from (nHct - sample mean of $\mathrm{nHct})^{2}$ in addition to its untransformed form to compensate for its nonlinear relationship with ARF-D (as identified by the cubic spline function analysis). ${ }^{22}$ In model 2 , nHct was categorized into 3 hemodilution groups: mild (nHct $>25 \%$ ), moderate (nHct $21 \%-25 \%$ ), and severe $(\mathrm{nHct}<21 \%)$. These cutoffs were defined by the 25 th and 75 th nHct percentiles. Each group was treated as a separate, independent variable in the logistic regression analysis. ${ }^{22}$ In sensitivity analyses, the robustness of the association between $\mathrm{nHct}$ and ARF-D was assessed by repeating model 2's regression analysis in 2 different subgroups: (1) excluding patients who had severe baseline renal dysfunction (defined as creatinine concentration more than twice the upper limit of normal) and were therefore at the highest risk for development of ARF-D and (2) including only patients who underwent isolated aortocoronary bypass (by providing a homogeneous patient population, this subgroup analysis removes many confounding issues, such as operative complexity, DHCA, and antifibrinolytic use). All models were constructed by using backward stepwise variable selection with $P \leq$ .05 as the criterion for variable retention. The models' fit was assessed by the Hosmer-Lemeshow (goodness-of-fit) test (a larger $P$ value means better fit or reliability), ${ }^{23}$ and predictive accuracy was assessed by the c-index (which is equivalent to the area under the receiver operating characteristic [ROC] curve; an area of 0.5 indicates no predictive discrimination and an area of 1.0 indicates perfect separation of patients with different outcomes). ${ }^{24}$

To explore the effects of risk adjustment on the association between nHct and ARF-D, the distributions of the other independent predictors of ARF-D (covariates in model 2) were obtained for each of the hemodilution groups. The bootstrap technique ${ }^{25}$ was used to assess validity of model 2 as follows: 100 computergenerated samples, each including 9000 patients, were derived from the study population by random selection with replacement. For each sample, model 2 was refitted, and the confidence intervals (CIs) for the coefficients of the nHct categories were obtained.

\section{Results}

During the study period, 9215 patients underwent cardiac operations with CPB. Fifty-seven patients were readmitted for additional operations necessitating CPB; only data from the first operation were used (ARF-D developed in none after either operation). Forty-seven patients with missing data and 88 patients with preexisting renal failure necessitating dialysis were excluded, leaving a total of 9080 patients for analysis. Database accuracy was more than $95 \%$.

The mortality rate was $1.7 \%(\mathrm{n}=150)$; the ARF-D rate was $1.5 \%(\mathrm{n}=134)$. The unadjusted relationships between ARF-D and the independent variables, including nHct as a continuous variable, are shown in Table 1. Figure 1 shows the spline function graph of the relationship between $\mathrm{nHct}$ and ARF-D. On the basis of the shape of this relationship, nHct was categorized as previously described into mild $(>25 \%)$, moderate $(21 \%-25 \%)$, and severe $(<21 \%)$ he- 


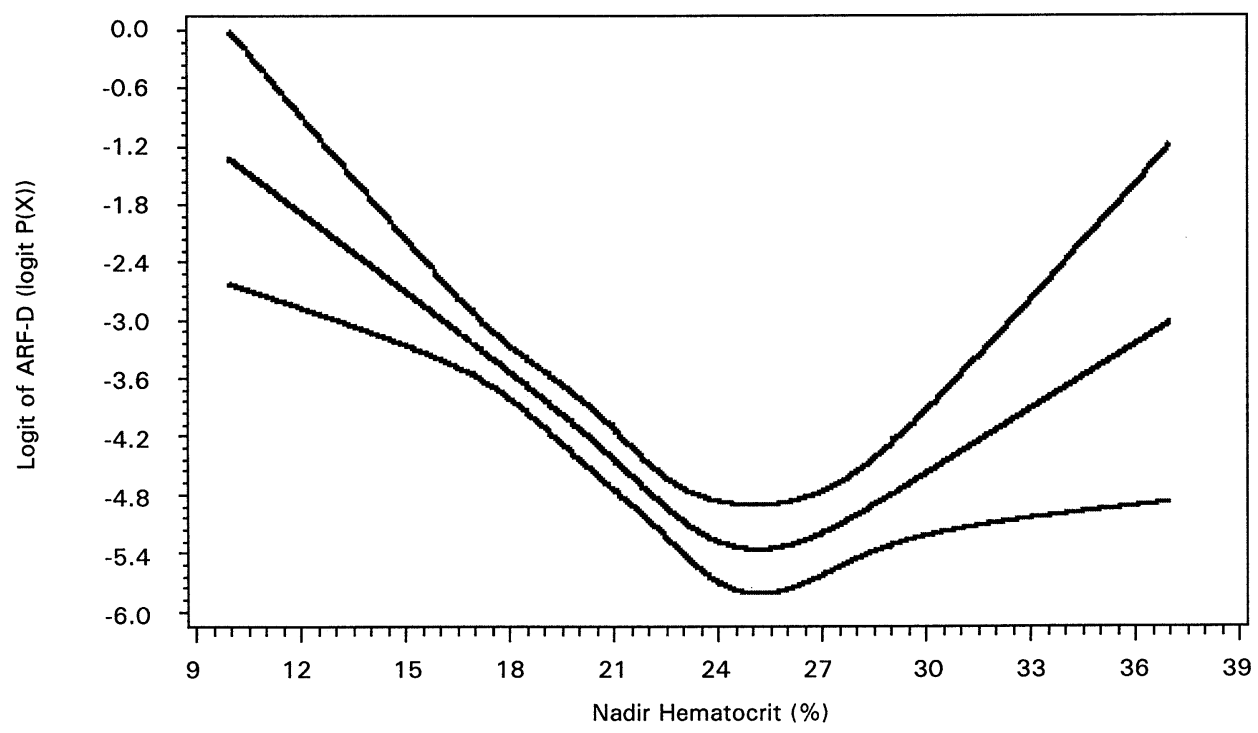

Figure 1. Estimated spline transformation and $95 \%$ confidence interval for nadir CPB hematocrit and acute renal failure necessitating dialysis (ARF-D).

modilution groups. The unadjusted relationship between ARF-D and nHct is presented in Figure 2.

The following baseline variables were associated with ARF-D and nHct by bivariate analysis: sex, weight, diabetes, peripheral vascular disease, cerebrovascular disease, atrial fibrillation, left ventricular ejection fraction, recent cardiac catheterization, shock, renal function, and hemoglobin concentration. The following intraoperative and postoperative variables were also associated: urgency, procedure type, highest blood glucose during $\mathrm{CPB}$, DHCA, excessive perioperative blood loss, difficult wean from $\mathrm{CPB}$, reexploration, low output syndrome, and serious adverse events. These variables, as well as age and CPB duration, were included in the logistic regression analysis.

In models 1 and 2, nHct was independently associated with ARF-D. In model 1, which included the quadratic form of nHct, the risk of ARF-D was increased as nHct deviated from the mean nHct of $23 \%(P=.005)$. The model was reliable (Hosmer-Lemeshow test, $P=.5$ ) and discriminative (c-index, 0.94). When nHct was included as 3 categorical variables, moderate hemodilution (nHct, 21\%-25\%) was associated with the lowest risk of ARF-D. Compared with moderate hemodilution, the odds ratio for ARF-D with severe hemodilution (nHct $<21 \%$ ) was $2.34(95 \%$ CI, 1.47 3.71 ), and for mild hemodilution (nHct $>25 \%$ ) it was 1.88 (95\% CI, 1.02-3.46). This model, which is presented in Table 2, was also reliable (Hosmer-Lemeshow test, $P=.4$ ) and discriminative (c-index, 0.94). The sensitivity analyses (Table 3) showed the adjusted odds ratio for ARF-D to be stable in the 2 patient subsets analyzed. The risk estimate for the mild-hemodilution group, however, was not as robust as the estimate for the severe-hemodilution group. Table 4 outlines the risk profile of the hemodilution groups in terms of the independent predictors of ARF-D (covariates in model 2). In all 100 bootstrap samples, nHct remained in the logistic regression model, with the $95 \%$ CI of the coefficients within $\pm 2 \%$ of those in model 2 .

\section{Discussion}

This study found that the degree of hemodilution during $\mathrm{CPB}$, as measured by $\mathrm{nHct}$, was independently related to the risk of ARF-D. After adjustment for multiple potential confounders, moderate hemodilution (nHct, $21 \%-25 \%$ ) was associated with the lowest risk of ARF-D, with the odds of ARF-D 2.34 times (95\% CI, 1.47-3.71) higher with severe hemodilution (nHct $<21 \%)$ and 1.88 times $(95 \%$ CI, $1.02-$ 3.46) higher with mild hemodilution ( $\mathrm{nHct}>25 \%$ ).

These adjusted odds ratios were markedly different from the unadjusted relationship between nHct and ARF-D (Figure 2). Adjustment for confounders reduced the risk of severe hemodilution and increased the risk of mild hemodilution relative to moderate hemodilution. This occurs because patients in the mild-hemodilution group have the most favorable risk profile and those in the severe-hemodilution group have the least favorable risk profile. The actual risk of ARF-D that is attributable to nHct, therefore, becomes evident only after these risk differences are accounted for by multivariate analysis.

The observed association between the degree of hemodilution during CPB and ARF-D is biologically plausible and is supported by existing literature. According to postmortem findings, the 2 most common etiologies for ARF after CPB are acute tubular necrosis caused by inadequate oxygen delivery and renal infarction caused, presumably, by micro- 

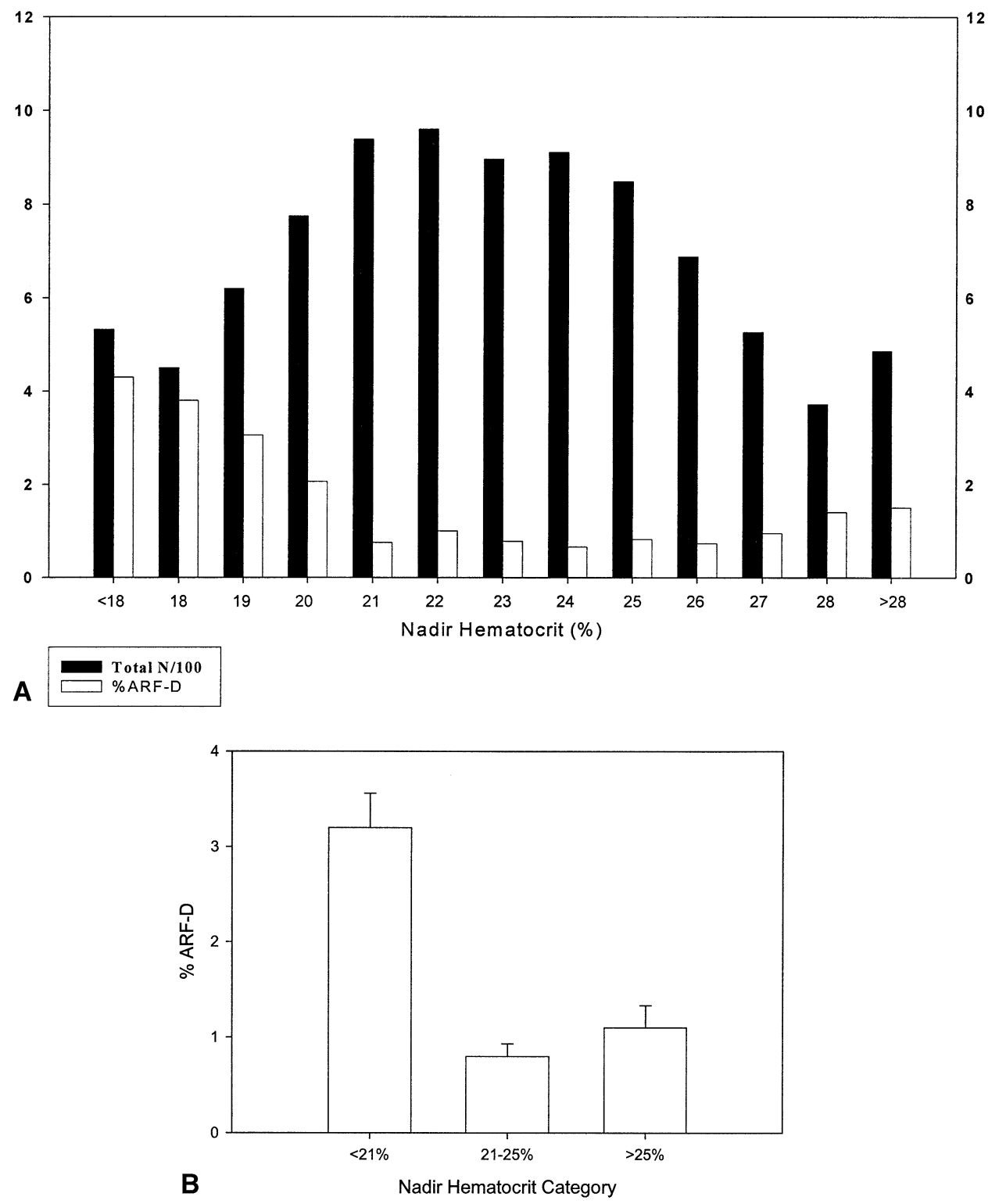

Figure 2. A, Unadjusted relationship between nadir CPB hematocrit and acute renal failure necessitating dialysis (ARF-D). B, Incidence of ARF-D in categories of nadir CPB hematocrit.

emboli. $^{26,27}$ The degree of hemodilution during CPB affects both renal oxygen delivery and renal embolic load.

\section{Hemodilution and Renal Oxygen Delivery}

Progressive hemodilution causes a proportional decrease in the oxygen-carrying capacity of the blood. As blood becomes more dilute, however, it also becomes less viscous, leading to increased blood flow in the macrocirculation and microcirculation. ${ }^{28,29}$ This increased flow compensates for the decreased oxygen-carrying capacity of blood, but only to an as-yet-undefined "critical" hematocrit concentration beyond which further hemodilution results in reduced tissue oxygen delivery. ${ }^{30}$ In vitro studies have found that even slight reductions in renal oxygen delivery can cause ischemic injury in certain highly susceptible areas of the kidney, especially if the kidney's energy requirements are increased. ${ }^{31,32}$ Hematocrit concentrations below this critical level would therefore place susceptible areas of the kidney at risk for ischemic injury. Further aggravating this risk may be the increased renal blood flow that occurs in response to hemodilution, which may increase the energy requirements of the kidney for tubular transport work by increasing renal perfusion and the glomerular filtration rate. ${ }^{31,33}$ Yet another aggravating factor is the proportional reduction in plasma oncotic pressure 
TABLE 2. Variables independently related to ARF-D: Results of the logistic regression model in which nadir hematocrit during CPB (nHCT) was included as 3 categorical variables

\begin{tabular}{|c|c|c|c|c|}
\hline Variable & Coefficient & SE & $\begin{array}{l}\text { Odds } \\
\text { ratio }\end{array}$ & $95 \% \mathrm{Cl}$ \\
\hline Intercept & 1.14 & 3.94 & & \\
\hline \multicolumn{5}{|l|}{ Preoperative variables } \\
\hline Diabetes mellitus (yes vs no) & 0.74 & 0.21 & 2.1 & $1.4-3.1$ \\
\hline Atrial fibrillation (yes vs no) & 0.88 & 0.29 & 2.4 & $1.4-4.2$ \\
\hline Renal function (abnormal vs normal) & 1.46 & 0.20 & 4.3 & $2.9-6.4$ \\
\hline Baseline hemoglobin (continuous; log trans) & -1.9 & 0.80 & 0.15 & $0.03-0.7$ \\
\hline Urgency (urgent vs elective) & 0.83 & 0.23 & 2.3 & $1.5-3.6$ \\
\hline \multicolumn{5}{|l|}{ Procedure } \\
\hline Complex vs isolated & 0.70 & 0.21 & 2.0 & $1.3-3.1$ \\
\hline \multicolumn{5}{|l|}{ ACB or single valve } \\
\hline \multicolumn{5}{|l|}{ Intraoperative variables } \\
\hline \multicolumn{5}{|l|}{ nHCT during CPB } \\
\hline$<21 \%$ vs $21 \%-25 \%$ & 0.35 & 0.16 & 2.34 & $1.47-3.71$ \\
\hline$>25 \%$ vs $21 \%-25 \%$ & 0.14 & 0.19 & 1.88 & $1.02-3.46$ \\
\hline \multicolumn{5}{|l|}{ Post-CPB variables } \\
\hline CPB weaning problems (yes vs no) & 1.13 & 0.23 & 3.1 & $2.0-4.8$ \\
\hline Re-exploration (yes vs no) & 1.32 & 0.22 & 3.7 & $2.4-5.8$ \\
\hline Low-output syndrome (yes vs no) & 1.33 & 0.23 & 3.8 & $2.4-5.9$ \\
\hline Adverse events (yes vs no) & 1.66 & 0.24 & 5.2 & $3.3-8.3$ \\
\hline
\end{tabular}

Hosmer-Lemeshow goodness-of-fit test $=0.4$; $\mathrm{c}$-index $=0.944$. $C l$, Confidence interval; $A C B$, aortocoronary bypass; $C P B$, cardiopulmonary bypass

TABLE 3. Sensitivity analyses*

\begin{tabular}{lccc}
\hline Sample & nHct & $\begin{array}{c}\text { Odds } \\
\text { ratio }\end{array}$ & $\mathbf{9 5 \%} \mathbf{~ C l}$ \\
\hline $\begin{array}{l}\text { Excluding patients with severe } \\
\text { preoperative renal } \\
\text { dysfunction }\end{array}$ & $<21 \%$ vs $21 \%-25 \%$ & 2.2 & $1.4-3.6$ \\
& $>25 \%$ vs $21 \%-25 \%$ & 1.6 & $0.9-2.9$ \\
$\begin{array}{l}\text { Including only patients who } \\
\text { underwent isolated ACB }\end{array}$ & $<21 \%$ vs 21\%-25\% & 3.4 & $1.7-6.8$ \\
& $>25 \%$ vs 21\%-25\% & 1.3 & $0.4-4.1$ \\
\hline
\end{tabular}

$n H c t$, Nadir hematocrit concentration; $C l$, confidence interval; $A C B$, aortocoronary bypass.

*Both models were developed by using the same strategy as model 2 (refer to text).

that occurs with hemodilution. This results in the accumulation of fluid in the interstitial space, which may ultimately lead to capillary closure and reduced tissue oxygen delivery. ${ }^{4,28,30}$

\section{Hemodilution and Renal Embolic Load}

The conduct of CPB generates a large number of emboli of various origins. ${ }^{34,35}$ The increase in renal blood flow associated with hemodilution may increase the relative number of emboli flowing to the kidneys, thereby increasing the risk of renal infarction and ARF.

These pathophysiological mechanisms provide an explanation for this study's finding that severe hemodilution is associated with a higher risk of ARF-D than is moderate hemodilution. This finding is also supported by other observational studies that have found a direct relationship between the severity of hemodilution and increasing risk of renal, hepatic, and central nervous system dysfunction, as well as mortality. ${ }^{6-11}$

The other finding of this study, that mild hemodilution may be associated with a higher risk of ARF-D than moderate hemodilution, is equally plausible. Hemodilution during CPB reduces red blood cell injury, ${ }^{29}$ an important cause of renal dysfunction. ${ }^{27,36}$ Furthermore, hemodilution prevents the deleterious trapping of red blood cells that occurs in the renal microvasculature after renal ischemia. ${ }^{12,13}$ Through these mechanisms, as well as by improving microcirculatory blood flow as described previously, moderate hemodilution may therefore confer more protection than mild hemodilution against ischemic renal injury. In contrast to this study, however, previous observational studies in cardiac surgery did not find an increased risk of renal dysfunction with mild compared with moderate hemodilution. ${ }^{6,11}$ This discrepancy may be due to differences in the definition of ARF, sample size, study population, distribution of nHct, or statistical analyses. Of note, this study's estimated association between ARF-D and mild versus moderate hemodilution was not as robust as that for severe versus moderate hemodilution, as is evident by the $95 \%$ CIs in both the primary (Table 2) and sensitivity (Table 3 ) analyses.

Several steps were taken in this study to ensure that the results were a valid estimate of the "true" relationship 
TABLE 4. Risk profile of the hemodilution groups with respect to covariates in model 2

\begin{tabular}{lccc}
\hline \multicolumn{1}{c}{ Covariate } & Severe hemodilution & Moderate hemodilution & Mild hemodilution \\
\hline Diabetes & $30.2 \%$ & $25.3 \%$ & $20.2 \%$ \\
Atrial fibrillation & $4.9 \%$ & $6.4 \%$ & $7.8 \%$ \\
Renal dysfunction & $24.2 \%$ & $19.0 \%$ & $14.7 \%$ \\
Baseline hemoglobin, g/dL (mean \pm SD) & $12.2 \pm 1.4$ & $13.5 \pm 1.3$ & $14.6 \pm 1.1$ \\
Nonelective procedure & $13.2 \%$ & $6.6 \%$ & $5.9 \%$ \\
Complex procedure & $23.5 \%$ & $23.6 \%$ & $30.7 \%$ \\
CPB weaning problems & $20.8 \%$ & $12.3 \%$ & $10.2 \%$ \\
Re-exploration & $7.4 \%$ & $5.7 \%$ & $5.8 \%$ \\
Low-output syndrome & $8.6 \%$ & $3.4 \%$ & $1.9 \%$ \\
Adverse events & $36.5 \%$ & $33.2 \%$ & $30.6 \%$ \\
\hline
\end{tabular}

$C P B$, Cardiopulmonary bypass.

between nHct during CPB and renal dysfunction. First, a clear and relevant measure of renal dysfunction-the need for dialysis-was used, as opposed to a surrogate measure, such as change in serum creatinine. ${ }^{37}$ Second, a prospectively collected and accurate database was used. Third, multiple confounders were identified and adjusted for, including several measures of severity of illness, intraoperative stability, surgical complexity, and perioperative complications. Moreover, sensitivity analyses were performed in different subgroups to further assess the role of several of the more important potential confounders. Fourth, logistic regression modeling was performed according to recommended guidelines, including using an appropriately large sample size (5 to 10 outcomes for each independent variable) and ensuring that the continuous independent variables were classified in such a manner as to conform to the linearity assumption of logistic regression. ${ }^{22}$ As a demonstration of the importance of the latter, when the nonlinear relationship of nHct with ARF-D was ignored and it was analyzed as a simple continuous variable, it was no longer independently associated with ARF-D (results not shown). Finally, this study included the entire cardiac surgery casemix of a single tertiary referral center in which patient management was standardized. This increases the generalizability of the results and at the same time ensures that the observed association is not due to variations in clinical practice.

\section{Study Limitations}

The results of our study must be interpreted cautiously for several reasons. First, the database was created before this study was conceived. Second, because it was an observational study, interpretation of the results should be limited to associations between variables of interest; no causal inferences should be drawn. Third, and most important, the influence of unmeasured but potentially confounding variables on the observed association cannot be entirely ruled out. For example, we did not collect, and therefore could not control for, patients' fluid balance. It is possible (but, given the standardized practice of CPB and fluid management at this institution, improbable) that patients with lower $\mathrm{nHct}$ were overhydrated and that those with higher nHct were underhydrated. Such a systematic difference in hydration status would confound the observed relationship between hemodilution during CPB and ARF-D. Other possible confounders include systematic differences in the type and the dose of colloids and antifibrinolytics, both of which may affect perioperative hemodilution and postoperative renal function. Fourth, given that the observed association between mild and moderate hemodilution was not significant in the subgroup analysis, it cannot be concluded that the risk of ARF-D is higher with mild versus moderate hemodilution. Larger studies are required to provide a more accurate estimate of this relationship.

\section{Clinical Implications}

Thus, despite the strengths of this study, we cannot recommend that the practice of CPB be modified to maintain patients' hematocrit concentration within the "optimal" range identified in this study. Before one can make such a recommendation, which would entail increasing the currently accepted transfusion trigger during $\mathrm{CPB}$, this finding must first be confirmed by randomized controlled trials that compare the renal effects of different hematocrit concentrations during $\mathrm{CPB}$. This is particularly important given that some of the available options for maintaining higher hematocrit concentrations during CPB are not risk free. For example, increasing the transfusion trigger during CPB may reduce the risk of ARF, but it will concomitantly expose patients to all the attendant risks of blood transfusion. Other options, such as retrograde priming of the CPB circuit with autologous blood, reducing the prime volume by using smaller circuits, and ultrafiltration during $\mathrm{CPB}$, may not be appropriate in every case and may increase costs.

On the basis of the results of this study, as well as those of other studies that have found an association between the degree of hemodilution during CPB and postoperative organ dysfunction and mortality, it is our conclusion that random- 
ized controlled trials comparing different degrees of hemodilution are now mandated to determine whether there is an "optimal" degree of hemodilution during CPB.

\section{References}

1. Chertow GM, Lazarus JM, Christiansen CL, Cook F, Hammermeister KE, Grover F, et al. Preoperative renal risk stratification. Circulation 1997;95:878-84

2. Mangano CM, Diamondstone LS, Ramsay JG, Aggarwal A, Herskowitz A, Mangano DT. Renal dysfunction after myocardial revascularization: risk factors, adverse outcomes, and hospital resource utilization. Ann Intern Med. 1998;128:194-203.

3. Provenchere S, Plantefeve G, Hufnagel G, Vicaut E, de Vaumas C, Lee $\mathrm{E}$, et al. Renal dysfunction after cardiac surgery with normothermic cardiopulmonary bypass: incidence, risk factors, and effect on clinical outcome. Anesth Analg. 2003;96:1258-64.

4. Hall TS. The pathophysiology of cardiopulmonary bypass: the risks and benefits of hemodilution. Chest. 1995;107:1125-33.

5. Jonas RA. Optimal hematocrit for adult cardiopulmonary bypass [letter]. J Cardiothorac Vasc Anesth. 2001;15:672.

6. Habib RH, Zacharias A, Schwann TA, Riordan CJ, Durham SJ, Shah A. Adverse effects of low hematocrit during cardiopulmonary bypass in the adult: should current practice be changed? J Thorac Cardiovasc Surg. 2003;125:1438-50.

7. Fang WC, Helm RE, Krieger KH, Rosengart TK, Du Bois WJ, Sason $\mathrm{C}$, et al. Impact of minimum hematocrit during cardiopulmonary bypass on mortality in patients undergoing coronary artery surgery. Circulation. 1997;96(suppl):II194-9.

8. De Foe GR, Ross CS, Olmstead EM, Surgenor SD, Fillinger MP, Groom RC, et al. Lowest hematocrit on bypass and adverse outcomes associated with coronary artery bypass grafting. Ann Thorac Surg. 2001;71:769-76

9. Jonas RA, Wypij D, Roth SJ, Bellinger DC, Visconti KJ, du Plessis AJ, et al. The influence of hemodilution on outcome after hypothermic cardiopulmonary bypass: results of a randomized trial in infants. J Thorac Cardiovasc Surg. 2003;126:1765-74.

10. Ranucci M, Pavesi M, Mazza E, Bertucci C, Frigiola A, Menicanti L, et al. Risk factors for renal dysfunction after coronary surgery: the role of the cardiopulmonary bypass technique. Perfusion. 1994;9:319-26.

11. Swaminathan M, Phillips-Bute BG, Conlon PJ, Smith PK, Newman MF, Stafford-Smith M. The association of lowest hematocrit during cardiopulmonary bypass with acute renal injury after coronary artery bypass surgery. Ann Thorac Surg. 2003;76:784-92.

12. Mason J, Welsch J, Torhorst J. The contribution of vascular obstruction to the functional defect that follows renal ischemia. Kidney Int. 1987;31:65-71.

13. Hellberg PO, Bayati A, Kallskog O, Wolgast M. Red cell trapping after ischemia and long-term kidney damage. Influence of hematocrit. Kidney Int. 1990;37:1240-7.

14. Yau TM, Fedak PW, Weisel RD, Teng C, Ivanov J. Predictors of operative risk for coronary bypass operations in patients with left ventricular dysfunction. J Thorac Cardiovasc Surg. 1999;118:100613.

15. Karkouti K, Cohen MM, McCluskey SA, Sher G. A multivariable model for predicting the need for blood transfusion in patients undergoing first-time elective coronary bypass grafting. Transfusion. 2001; 41:1193-203.

16. Eriksen BO, Hoff KR, Solberg S. Prediction of acute renal failure after cardiac surgery: retrospective cross-validation of a clinical algorithm. Nephrol Dial Transplant. 2003;18:77-81.

17. Parr KG, Patel MA, Dekker R, Levin R, Glynn R, Avorn J, et al. Multivariate predictors of blood product use in cardiac surgery. J Cardiothorac Vasc Anesth. 2003;17:176-81.
18. Covin R, O'Brien M, Grunwald G, Brimhall B, Sethi G, Walczak S, et al. Factors affecting transfusion of fresh frozen plasma, platelets, and red blood cells during elective coronary artery bypass graft surgery. Arch Pathol Lab Med. 2003;127:415-23.

19. Devlin TF, Weeks BJ. Spline functions for logistic regression modeling. In: Proceedings of the 11th Annual SAS Users Group International Conference. Cary (NC): SAS Institute Inc; 1986. p. 646-51.

20. Harrell FE. SAS macros and data step programs useful in survival analysis and logistic regression. 1986. Available at: http://biostat. mc.vanderbilt.edu/twiki/bin/view/Main/SasMacros. Vanderbilt University School of Medicine; Nashville (TN); Accessed August 23, 2004.

21. Harrell FE, Lee KL, Pollock BG. Regression models in clinical studies: determining relationships between predictors and response. $J$ Natl Cancer Inst. 1988;80:1198-202.

22. Katz MH. Multivariable analysis: a practical guide for clinicians. Cambridge: Cambridge University Press; 1999.

23. Feinstein AR. Multiple logistic regression. In: Feinstein AR, editor. Multivariable analysis: an introduction. New Haven (CT): Yale University Press; 1996. p. 297-330.

24. Ash AS, Shwarz M. Evaluating the performance of risk-adjustment methods: dichotomous outcomes. In: Iezzoni LI, editor. Risk adjustment for measuring healthcare outcomes. Chicago: Health Administration Press; 1997. p. 427-70.

25. Efron B, Tibshirani RJ. Estimates of bias. In: Cox DR, Hinkley DV, Reid N, Rubin DB, Silverman BW, editors. An introduction to the bootstrap. New York: Chapman \& Hall; 1993. p. 124-40.

26. Yeboah ED, Petrie A, Pead JL. Acute renal failure and open heart surgery. Br Med J. 1972;1:415-8.

27. Krian A. Incidence, prevention, and treatment of acute renal failure following cardiopulmonary bypass. Int Anesthesiol Clin. 1976;14:87101.

28. Chen Y, Berglin E, Belboul A, Roberts D. A mathematical analysis of haemorheologic factors during cardiopulmonary bypass for congenital heart disease. Perfusion. 1995;10:431-8.

29. Chen Y, Belboul A, Berglin E, Roberts D. A mathematical analysis of hemorheological changes during heart valve replacement. J Cardiovasc Surg. 2000;41:37-43.

30. Ereth MH, Oliver WC, Santrach PJ. Intraoperative techniques to conserve autologous blood: red-cell savage, platelet-rich plasma, and acute normovolemic hemodilution. In: Spiess BD, Counts RB, Gould SA, editors. Perioperative transfusion medicine. Baltimore: Williams \& Wilkins; 1998. p. 325-50.

31. Ratcliffe PJ, Endre ZH, Tange JD, Ledingham JG. Ischaemic acute renal failure: why does it occur? Nephron. 1989;52:1-5.

32. Brezis M, Rosen S, Silva P, Epstein FH. Renal ischemia: a new perspective. Kidney Int. 1984;26:375-83.

33. Mielke JE, Hunt JC, Maher FT, Kirklin JW. Renal performance during clinical cardiopulmonary bypass with and without hemodilution. J Thorac Cardiovasc Surg. 1966;51:229-37.

34. Moody DM, Bell MA, Challa VR, Johnston WE, Prough DS. Brain microemboli during cardiac surgery or aortography. Ann Neurol. 1990; 28:477-86

35. Borger MA, Ivanov J, Weisel RD, Rao V, Peniston CM. Stroke during coronary bypass surgery: principal role of cerebral macroemboli. Eur J Cardiothorac Surg. 2001;19:627-32.

36. Loef BG, Epema AH, Navis G, Ebels T, van Oeveren W, Henning RH. Off-pump coronary revascularization attenuates transient renal damage compared with on-pump coronary revascularization. Chest. 2002;121: $1190-4$.

37. Wijeysundera DN, Rao V, Beattie WS, Ivanov J, Karkouti K. Evaluating surrogate measures of renal dysfunction after cardiac surgery. Anesth Analg. 2003;96:1265-73. 